\title{
Interannual Variation in Snow-accumulation Events in Tokyo and its Relationship to the Eurasian Pattern
}

\author{
Yoshihiro Tachibana ${ }^{1}$, Tetsu Nakamura ${ }^{2}$, and Nobuhiro Tazou ${ }^{3,4}$ \\ ${ }^{1}$ Institute of Observational Research for Global Change, JAMSTEC, Yokosuka, Japan \\ ${ }^{2}$ Graduate School of Earth and Environmental Science, Tokai University, Hiratsuka, Japan \\ ${ }^{3}$ Department of Aeronautics and Astronautics, Tokai University, Hiratsuka, Japan \\ ${ }^{4}$ East Japan Railway company, Japan
}

\begin{abstract}
We examined interannual variation in snowaccumulation events in Tokyo and the relationship of this variation to large-scale atmospheric patterns. Years when snow-accumulation events occurred tended to coincide with a west-to-east wavetrain pattern in the middle and upper troposphere over Eurasia. The pattern, which includes cyclonic anomalies over Europe and East Asia and anticyclonic anomalies over Siberia, is identical to the negative phase of the Eurasian (EU) pattern, which is the leading mode of an empirical orthogonal function (EOF) analysis applied for the Eastern Hemisphere in the 500-hPa height field. Anomalous cold air associated with the negative EU pattern widely covers East Asia and Japan in the lower troposphere. No significant relation to storm-track activities around Japan was found except for extremely deep snowfall years. The cold atmospheric anomaly associated with the negative EU pattern possibly lowers the surface air temperature over Tokyo, creating an environment favorable to snowfall and snow accumulation. In the extremely deep snow years, the signature of the EU pattern was weak, and storm tracks over the ocean to the south of Japan were significantly active. No clear long-term trend in snow-accumulation events was found, although a downward trend due to anthropogenic effects was expected.
\end{abstract}

\section{Introduction}

Even a few centimeters of snow accumulation in Tokyo can cause massive traffic congestion and railservice delays. As Tokyo is a key center of global and national economic and political activities, disruptions caused by snowfall can negatively affect the Japanese economy. Thus, the ability to provide long-term forecasts of snowfall in Tokyo is important. However, many previous meteorological studies have focused on shortterm forecasts or on events such as the relationship between snowfall in Tokyo and the location and path of cyclones (e.g., Ito 1956; Yamamoto 1984). Furthermore, while numerous past studies have examined snowfall in Tokyo and synoptic-scale conditions (e.g., Ito 1956; Yamamoto 1984; Yasuda and Tomine 1998), the lack of research from a global-scale perspective has prevented long-term forecasting.

Large-scale atmospheric modes that may be related to the winter climate of Japan include the Arctic Oscillation (AO), Western Pacific (WP) pattern, and Eurasian (EU) pattern. The WP pattern is a north-south dipole pattern around Japan that is related to snowfall

Corresponding author: Yoshihiro Tachibana, Institute of Observational Research for Global Change, Japan Agency for Marine-Earth Science and Technology, 2-15 Natusihima, Yokosuka 237-0061, Japan. E-mail: tachi@jamstec.go.jp. (C) 2007, the Meteorological Society of Japan.

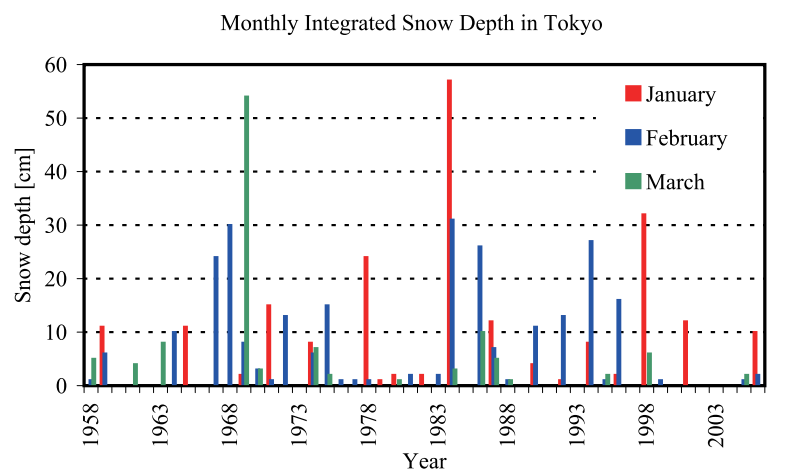

Fig. 1. Monthly integrated snow depth in Tokyo in each month of each year.

in regions along the Sea of Japan (Tachibana et al. 2007). The EU pattern is a west-east wavetrain pattern that originates over western Europe and moves toward Japan (Wallace and Gutzlar 1981). The EU pattern is connected to amplification of AO (Ohashi and Yamazaki 1999). Thompson and Wallace (2000) examined the link between the $\mathrm{AO}$ and extreme meteorological events around the world, briefly mentioning the association of AO with snowfall in Tokyo. However, no previous studies have considered in detail the interannual variation in snowfall in Tokyo and its relationship to largescale atmospheric teleconnection patterns, which is the focus of this paper.

\section{Data and methods}

The analysis period was 1958 through 2006. Snow data were obtained from the monthly archives of the Tokyo Meteorological Weather Station, which is located in the center of Tokyo and operated by the Japan Meteorological Agency (JMA; data available at www. data.kishou.go.jp). We analyzed data from January through March, the months when snowfall is most likely in Tokyo. Using the snow-depth data, we classified each month of all study years into two categories: months in which snow accumulation was observed, regardless of snow depth, and months in which no snow accumulation was observed. Based on this categorization, we then examined the statistical differences in large-scale atmospheric circulations and sea surface temperatures (SSTs). Additionally, we analyzed the extremely deep snowfall months in which the snow was deeper than or equal to $10 \mathrm{~cm}$.

Daily data from the National Centers for Environmental Prediction/National Center for Atmospheric Research (NCEP/NCAR) reanalysis dataset were used to analyze the large-scale atmospheric fields and determine storm-track activity. We defined storm tracks by $(v-\bar{v})(T-\bar{T})$, where $T$ and $v$ are daily temperature and daily meridional component of the wind at $850 \mathrm{hPa}$ re- 
spectively, and $\bar{T}$ and $\bar{v}$ are 5 -day-mean values. The value of $(v-\bar{v})(T-\bar{T})$ was calculated day by day. The monthly mean value of $(v-\bar{v})(T-\bar{T})$ was then derived as the monthly mean storm track to estimate the climatological storm track and its interannual deviation. According to this formulation, we extracted the variability with a timescale shorter than 5 days. To examine the relationship with environmental SSTs, Global Sea Ice and Sea Surface Temperature data (GISST) from 1958 through 2000 were also used.

We also analyzed the snow data of some neighboring JMA stations. Overall results are almost identical to those found in Tokyo. Therefore the results shown in this paper are applicable not only to Tokyo but also to the area around Tokyo.

\section{Interannual variation}

Figure 1 shows the interannual variation in snow depth, illustrating that most snowfall occurs in February. In more than half of the years studied, Tokyo experienced snow accumulation in February. In January and March, snow accumulation occurred in about half and one-third of the years, respectively. However, in December, snow accumulation was recorded in only 6 years (not shown). Because there were so few snowaccumulation events in December, we examined only January, February, and March in this study. Both the earliest and most recent periods tended to show fewer snow-accumulation months compared to the middle of the period studied. There was no prominent downward trend in any of the months, although a downward trend due to global warming and warming caused by the urban heat island effect was expected. Therefore, we rejected the popular notion that snowfall has been decreasing due to anthropogenic effects, at least during the latter half of the last century and from the viewpoint of the number of months having snow accumulation.

\section{Relationship to large scale patterns}

Based on Fig. 1, we classified all months (i.e., 147 months from 1958 through 2006) into two categories: snow-accumulation months $(n=61)$ and no-snow months $(n=86)$. Anomaly fields of the NCEP/NCAR reanalysis data and SST data in each month from the monthly climatology were prepared in advance. Composite large-scale anomaly patterns of snow months were then calculated (Fig. 2). The 500-hPa height pattern shows negative anomalies over western Europe and the Russian Far East, whereas positive anomalies are located in between these areas. Similar patterns were also found in the upper troposphere (figures not shown). The $1000-\mathrm{hPa}$ height field reveals negative anomalies over western Europe and positive anomalies over Siberia and Japan. The local circulation pattern around Japan implies the presence of eastern geostrophic wind anomalies over Japan, although overall the anomalies do not reach the level of statistical significance. Significant cold anomalies widely cover the Russian Far East and East Asia in the 850-hPa temperature field. The temperature pattern is similar to that of the $500-\mathrm{hPa}$ height, although the signatures over Europe and Siberia are weak. Japan is located at the eastern edge of the cold anomalies.

This cross-continental negative-positive-negative pattern resembles the teleconnection of the EU pattern. To confirm this, we objectively extracted the leading mode of the $500-\mathrm{hPa}$ height over the Eurasian continent by empirical orthogonal function (EOF) analysis with an area-weighted covariance matrix using the 147-month anomaly fields. The area of the EOF calculation covered

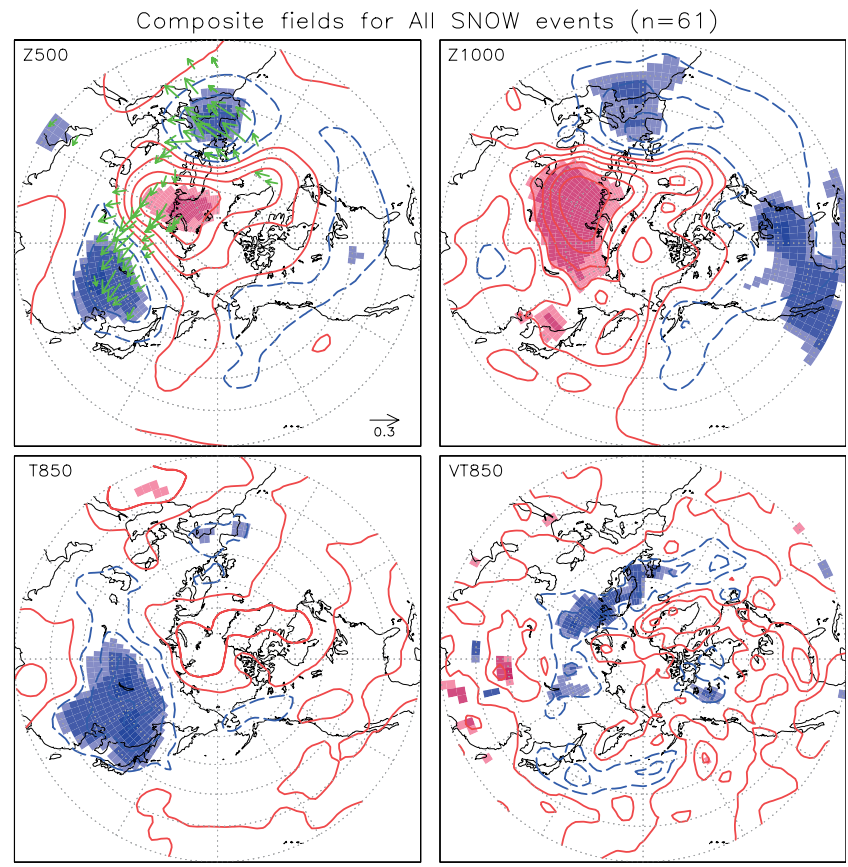

Fig. 2. Composite large-scale atmospheric fields for snowaccumulation events (top left) for the $500-\mathrm{hPa}$ height field and the wave activity flux defined by Takaya and Nakamura (2001), (top right) for the 1000-hPa height field, (bottom left) for the $850-\mathrm{hPa}$ temperature field, and the storm track (bottom right). Gradations of shading indicate statistical significance exceeding 90,95 , and $99 \%$ by $t$-tests, in which we assume that all the monthly mean values are independent. Shades of red and blue correspond to positive and negative anomalies, respectively. The height and temperature are in meters and Kelvin, respectively. The unit length of the wave activity flux is shown in the bottom-right corner $\left(0.3 \mathrm{~m} \mathrm{~s}^{-2}\right)$. The contour intervals are $5 \mathrm{~m}, 3 \mathrm{~m}, 0.3 \mathrm{~K}$, and $0.5 \mathrm{~K} \mathrm{~m} \mathrm{~s}^{-1}$ for the $500-\mathrm{hPa}$ height, 1000-hPa height, temperature, and storm track respectively.

approximately the Eastern Hemisphere from $20^{\circ} \mathrm{W}$ to $160^{\circ} \mathrm{E}$ and $30^{\circ} \mathrm{N}$ to $67.5^{\circ} \mathrm{N}$. The leading EOF explains about $22 \%$ of the total variability. Figure 3 shows composite patterns of the leading mode. The pattern of the $500-h P a$ height is almost identical to the snow-month pattern shown in Fig. 2. In both, the patterns of the wave activity flux move from Europe toward the Far East. The flux of the EOF is stronger for Europe than for the Far East, and the flux of the snow months is stronger over the Far East than for Europe. The overall similarities in the two figures indicate that the largescale pattern related to snow in Tokyo is that of Rossby waves traveling from Europe to the Far East and that this wave pattern is a leading mode over Eurasia. The patterns in the lower troposphere of the EOF leading mode in the Eastern Hemisphere were also similar to that of snow events in Tokyo (Figures not shown). The $500-\mathrm{hPa}$ height amplitude shown in Fig. 2 is smaller than that in Fig. 3. This small amplitude can result from the fact that some snow events exceptionally occurred even in the positive phase of the EU pattern. The occurrence rates of the snow event in negative EU months were $42 \%$ for the months of the extremely large negative EU index (negatively exceeded minus one standard deviation), and $49 \%$ for the months of the non-extreme negative EU index (the other months with the negative EU index). On the other hand, 26\% of the extreme EUpositive months experienced the snow. Therefore, the months with the negative EU index can experience the snow with higher probability than those with the 
Composite Fields for Negative EU $(n=18)$

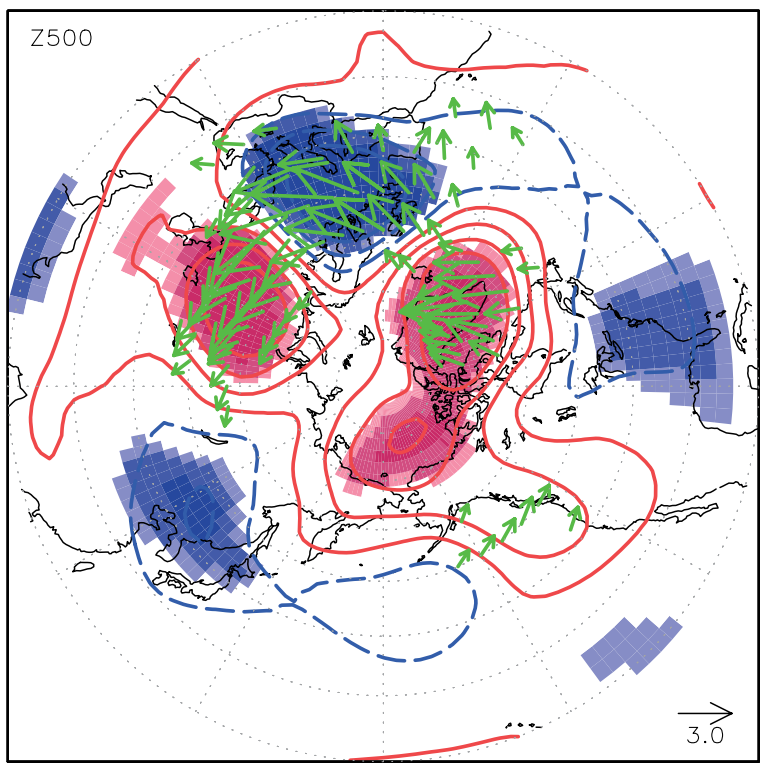

Fig. 3. As in Fig. 2, except for composite 500-hPa fields of the leading EOF. The months $(n=18)$ in which the amplitude of the time coefficient of the EOF negatively exceeded minus one standard deviation were chosen for the composite. The contour intervals are $15 \mathrm{~m}, 10 \mathrm{~m}$. The unit length of the wave activity flux is shown in the bottom-right corner and has a value of 3 $\mathrm{m} \mathrm{s}^{-2}$.

positive EU index. This implies that other hidden factors are also related to the snow.

The patterns shown in Figs. 2 and 3 are similar to that of a negative phase of the EU pattern identified by Wallace and Gutzlar (1981), who also showed a westeast wave pattern over Eurasia. However, the spatial phases of the present figures differ from those reported by Wallace and Gutzlar (1981), with the action centers of the geopotential height of Wallace and Gutzlar (1981) located at the nodes in our study. Instead, our patterns more closely resemble the EU patterns identified by rotated EOF analysis by Barnston and Livezey (1987), or "type 1" of the EU pattern classified by Ohashi and Yamazaki (1999). Although identification of the EU pattern depends somewhat on the definition used, for this study we considered the cross-continental pattern shown by the present EOF analysis to be the EU pattern.

Because cyclones directly bring snow events, we also examined the relationship between storm-track activity and snow in Tokyo. No statistically significant signature of storm-track activity was observable around Japan (bottom right of Fig. 2). However, as pointed out by Ito (1956) and Yamamoto (1984), the path of midlatitude cyclones tends to be to the south of Japan when snowfall occurs in Tokyo. This suggests that storm activity around Japan is not the primary determinant of snowfall events in Tokyo at the interannual time scale.

Next, large-scale anomaly patterns of the extremely deep snowfall months in which the snow was deeper than or equal to $10 \mathrm{~cm}$ are demonstrated (Fig. 4). Overall patterns are different from those in Fig. 2. The EU-like signatures is weak in the $500-\mathrm{hPa}$ and $1000-\mathrm{hPa}$ height fields. This indicates that connection to the EU pattern is stronger in the non-extreme snow months than in the extremely deep snowfall months. In fact, there was only one extremely deep snowfall month in the extreme negative EU months in which the EU index negatively exceeded minus one standard deviation. The connection of the storm track around Japan is more significant than Fig. 2. An active storm-track area is located over the Pacific Ocean to the south of Japan. This strengthened storm track is in agreement with the points by Ito (1956) and Yamamoto (1984).

\section{Relationship to SSTs}

Sea-surface temperatures were remotely related to the snow and EU patterns. Figure 5 presents composite SST anomalies in the snow months and in the months with an anomalous value of the leading EOF. In snow months, negative anomalies widely cover the midlatitude North Pacific Ocean, while positive anomalies occur off the coast of western North America. This structure is somewhat similar to the Pacific Decadal oscillation (PDO) introduced by Mantua et al. (1997), even though the tropical Pacific signature is absent. The absence of a signature in the tropical Pacific also indicates that the El Niño-Southern Oscillation (ENSO) is not related to the snow in Tokyo. Over the North Atlantic, a significant tripole pattern, which interacts with the North Atlantic Oscillation (e.g., Rodwell et al. 1999; Tanimoto and Xie 2002), has been associated with the EU pattern. Also the PDO may be related to longterm multi-decadal variations of the snow in Tokyo. Local SSTs are negative around Japan, although their signatures do not reach a significant level in the snow months.

\section{Discussion and remarks}

We examined long-term variation in snowaccumulation events in Tokyo and the relationship of this variation to large-scale atmospheric patterns and surrounding SSTs. The large-scale atmospheric pattern was closely related to the EU pattern, suggesting that

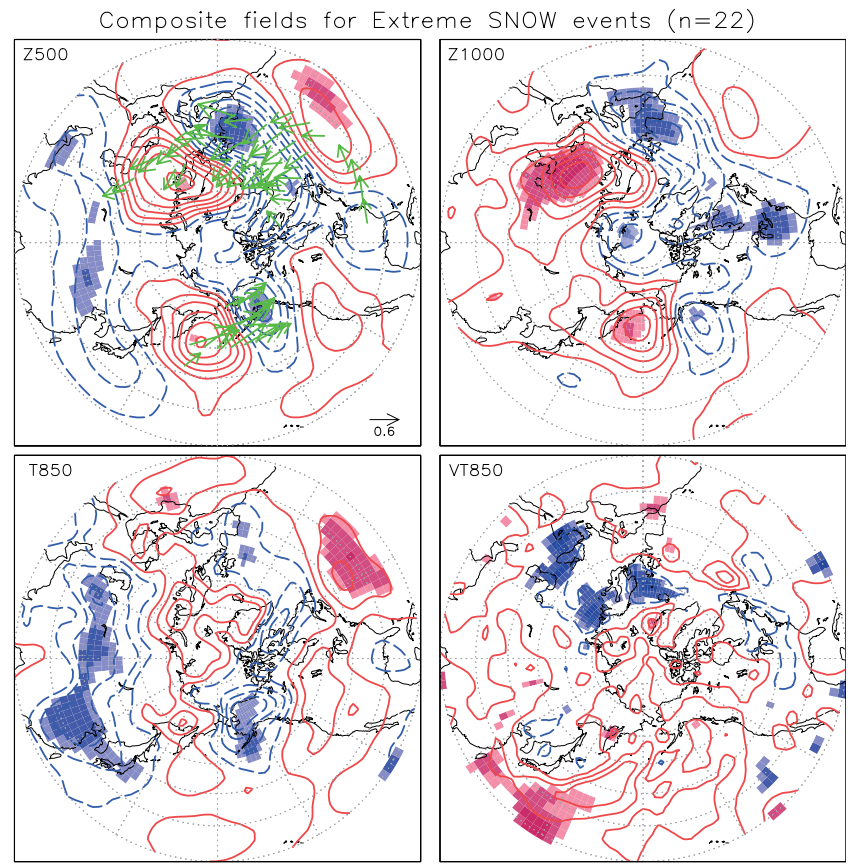

Fig. 4. As in Fig. 2, except for the extremely deep snowfall months $(n=22)$. The unit length of the wave activity flux is shown in the bottom-right corner $\left(0.6 \mathrm{~m} \mathrm{~s}^{-2}\right)$. The contour intervals are $5 \mathrm{~m}, 5 \mathrm{~m}, 0.3 \mathrm{~K}$, and $1 \mathrm{~K} \mathrm{~m} \mathrm{~s}^{-1}$ for the $500-\mathrm{hPa}$ height, 1000-hPa height, temperature, and storm track respectively. 


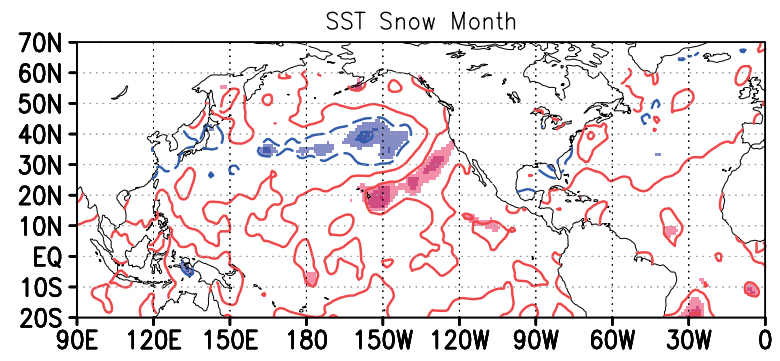

SST EOF 1

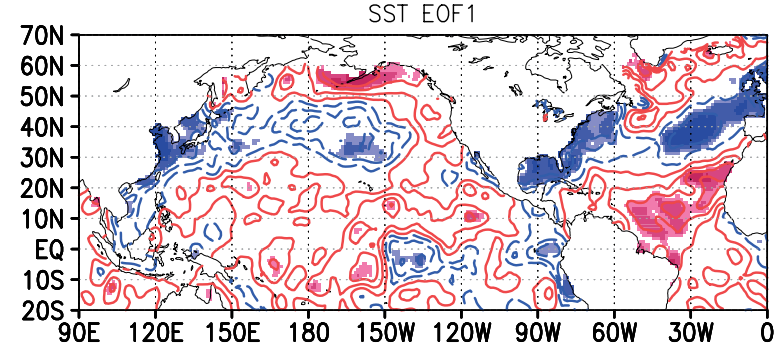

Fig. 5. As in Fig. 2, except for composite SST anomalies in the snow months $(n=61)$ (Top). As in Fig. 3, except for composite SST in association with the leading $\operatorname{EOF}(n=18)$ (Bottom). Contour intervals of both figures are $0.1 \mathrm{~K}$.

the EU pattern is a key factor in snow-accumulation events in Tokyo at the interannual time scale. In years when snow accumulation occurred in Tokyo, the EU pattern tended to be negative (i.e., negative height anomalies over Europe, positive anomalies over central Siberia, and negative anomalies over the Far East). In addition, anomalously cold temperatures in the lower troposphere around East Asia were found in association with the EU pattern. Local SSTs around Japan were also slightly colder. The cold conditions in East Asia associated with the EU pattern corresponded to surface cold anomalies coupled with the upper tropospheric stationary Rossby wavetrain over Eurasia (Takaya and Nakamura 2005). These colder-than-normal conditions may lower the surface air temperature in Tokyo, creating more potential for precipitation to form into snow as the wintertime climatological surface air temperature of Tokyo nears freezing (e.g., Yamamoto 1984; Yasuda and Tomine 1998). Easterly or northeasterly winds in the lower troposphere may supply moist maritime air masses, and hence possible precipitation, to Tokyo, which is located at the southeastern edge of the main island of Japan. Storm-track activities around Japan were not significantly correlated with the variation in the EU pattern. Although this suggests that cyclone movement is not connected with the EU pattern in its negative phase, the colder environments in negative EU years may lead to some precipitation associated with cyclones falling as snow, which may accumulate in Tokyo. However, the cold anomalies around Japan are not large. This suggests the existence of other unknown processes. Further researches are needed in the future.

In the month of the extremely deep snowfall, largescale patterns are not strongly related to the EU pattern. The storm track is significantly active over the ocean located to the south of Japan in contrast to the nonextreme snow months. This connection to the storm track is in agreement with the previous studies pointed out by Ito (1956) and Yamamoto (1984), in which the path of mid-latitude cyclones tends to be to the south of Japan when snowfall occurs in Tokyo. The large-scale 500-hPa height field in Fig. 4 also signifies the tendency of a southward shift of the jet around Japan although values do not reach a significant level. This southward shift of the jet can be in association with the large storm-track activity over the ocean to the south of Japan.

No significant negative long-term trend in snowfall events was found, although anthropogenic effects may play a strong role in the climatic warming tendency in Tokyo. Because the EU pattern also showed no significant trend, the absence of a trend in snowfall events is reasonable. However, studies have identified signatures of multi-decadal timescales in the EU pattern (e.g., Ohashi and Yamazaki 1999). Further research on the formation mechanism of the EU pattern, as well as its long-term variations, is needed for more accurate longterm forecasts. This study focused only on whether snow accumulated. Further studies on the long-term variation in snow depth and its relationship to variations in large-scale patterns are the next research step.

\section{Acknowledgments}

We thank K. Hashimoto for his assistance of the calculation of the storm track. Advices of anonymous reviewers were quite fruitful for the revision. GrADS was used for drawing the figures.

\section{References}

Barnston, A. G., and R. E. Livezey, 1987: Classification, seasonality and persistency of low-frequency atmospheric circulation patterns, Mon. Wea. Rev., 115, 1083-1126.

Ito, K., 1956: Snowfall in Tokyo, J. Japanese Soc. Snow and Ice, 18, 25-27 (in Japanese).

Mantua, N. J., S. R. Hare, Y. Zhang, J. M. Wallace, and R. C. Francis, 1997: A Pacific decadal climate oscillation with impacts on salmon. Bull. Ameri. Meteor. Soc., 78, $1069-$ 1079 .

Ohashi, Y., and K. Yamazaki, 1999: Variability of the Eurasian pattern and its interpretation by wave activity flux, $J$. Meotor. Soc. Japan, 77, 495-511.

Rodwell, M. J., D. P. Rowell, and C. K. Folland, 1999: Oceanic forcing of the wintertime North Atlantic Oscillation and European climate, Nature, 398, 320-323.

Tachibana, Y., Y. Takano, and K. Iwamoto, 2007: Anomalous climates over the seas of Japan and Okhotsk in the winter of 2005/06 and their relation to the heat and moisture budgets, Meteor. Res. Note, 216, 161-166 (in Japanese).

Takaya, K., and H. Nakamura, 2001: A formulation of a phaseindependent wave-activity flux for stationary and migratory quasi geostrophic eddies on a zonally varying basic flow, J. Atmos. Sci., 58, 608-627.

Takaya, K., and H. Nakamura, 2005: Mechanisms of intraseasonal amplification of the cold Siberian High. J. Atmos. Sci. 62, 4423-4440.

Tanimoto, Y., and S.-P. Xie, 2002: Inter-hemispheric decadal variations in SST, surface wind, heat flux and cloud cover over the Atlantic Ocean. J. Meteor. Soc. Japan, 80, 11991219.

Thompson, D. W., and J. M. Wallace, 2000: Regional climate impacts of the Northern Hemisphere annular mode, Science, 293, 85-89.

Yamamoto, A., 1984: Snowfalls in the Kanto Plain -Threshold air temperature for snowfalls in the melting layer-, $J$. Meteor. Res., 36, 131-149 (in Japanese).

Yasuda, T., and K. Tomine, 1998: Relations between types of precipitation and temperature profiles over Kanto area, Tenki, 45, 171-186 (in Japanese).

Wallace, J. M., and D. S. Gutzler, 1981: Teleconnections in the geopotential height field during the Northern Hemisphere winter. Mon. Wea. Rev., 109, 784-812.

Manuscript received 31 October 2007, accepted 7 December 2007 SOLA: http://www.jstage.jst.go.jp/browse/sola/ 